\title{
DETERMINATION OF STRESSES IN THE AXLE PIN BASED ON THE WIND MODEL IN THE WIND TURBINE
}

\begin{abstract}
Summary
Even when all the details are provided, the design of wind turbines is a big challenge. The detailed knowledge of the deformation of vital wind turbine components caused by a wind with extreme operating gusts and other type of winds can be obtained only by performing measurements on the wind turbine. The vital component of the wind turbine is axle pin. This article presents the results of the measured changes in wind speed at the height at which strains were measured. The measured strains are used for calculating the stress. It is also shown that on the basis of the calculations on the wind model obtained with the GH Bladed software, the input data are obtained for the SolidWorks software, by which stress on the axle pin can be calculated. The final confirmation of the proper approach and the calculation is achieved by comparison between the calculated and the measured strains on the axle pin during exploitation of a wind turbine of nominal power output of $1 \mathrm{MW}$.
\end{abstract}

Key words: $\quad$ wind turbine, axle pin, principal stresses, measuring rosette

\section{Introduction}

Reliable production of electricity depends among others parameters on the axle pin of the wind turbine. Mechanically, the axle pin is the most critical part of the wind turbine and is loaded by bending (not torsion). It is connected with the hub by means of main bearings [1] and it is usually made of steel by a casting process. Changes in wall thicknesses and a reduction in diameters can cause defects in the material, such as pores, flaws or slag. Therefore, for reliable use, it is necessary to perform structural integrity assessment of the axle pin for flaws, such as cracks [1,2].

In the eastern Adriatic, the construction of wind farms began only 15 years ago and wind farms are still built and developed. Currently, in Croatia there are much less wind turbines in operation than in other countries of Southern and Western Europe. The reason lies in the adoption of technology by local companies and subcontractors, as well as in the characteristics of the winds blowing along the eastern Adriatic coast, which are not favourable for building wind turbines as, for example, in northern Germany or Denmark. This article analyses loading of wind turbines on potentially appropriate sites for building a wind farm. Wind characteristics are the boundary condition for the construction and installation of wind 
turbines. The wind farm included in this study is located at the Croatian coast, Dalmatia, in Pometeno Brdo. There extensive wind measurements were carried out by the Meteorological and Hydrological Institute of the Republic of Croatia. The wind rose and the annual mean wind speed showed that the area of Dalmatia is the most adequate region in Croatia to set up wind farms with the capacity of $800 \mathrm{~kW}$ to $2 \mathrm{MW}$. The wind rose, compiled for a wider area of Split at two locations (no. 5 and 14), shown that the winds from the north-eastern and southwestern directions are most common, as shown in Fig. 1 [3]. Annual mean wind speed measured over years shows that the northeast wind force varies from 2.8 to 3.8 Beaufort, which corresponds to the category of moderate wind. Thus, the Split area is more favourable for building wind farms than the area of Senj for example, where the wind is too strong, or Zadar, as shown in Fig. 2, where the wind is light [4]. Fig. 3 shows a location of anemograph stations in Croatia [5] and the planned location for wind farms, in particular Pometeno Brdo [1]. After defining the distribution of wind speeds using the Rayleigh model, it is possible to show the distribution of electricity production by applying certain correlation [6,7]. The largest wind turbine electricity production occurs at wind speeds between 10 and $13 \mathrm{~m} / \mathrm{s}$, while at higher speeds exceeding $20 \mathrm{~m} / \mathrm{s}$ the utilization of the electrical generating unit is less, i.e., the operation of the wind turbine stops due to overload. The prototype, a wind turbine with a nominal power of 1 MW was put into full operation in May 2009. Fig. 4 shows the wind direction (Northeast wind) and wind speed (3.4 to $5.5 \mathrm{~m} / \mathrm{s}$ ) over a period of 6 hours on May 30, 2009.

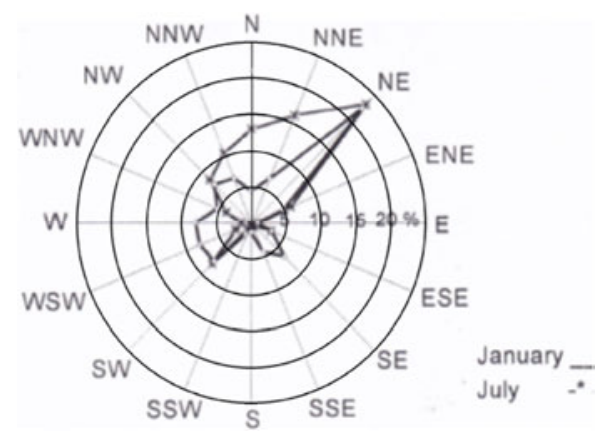

Fig. 1 Wind rose at $850 \mathrm{hPa}$ during burin and bora, wind direction and speed at Split-Marjan, January and July, 1977-1986. [3]

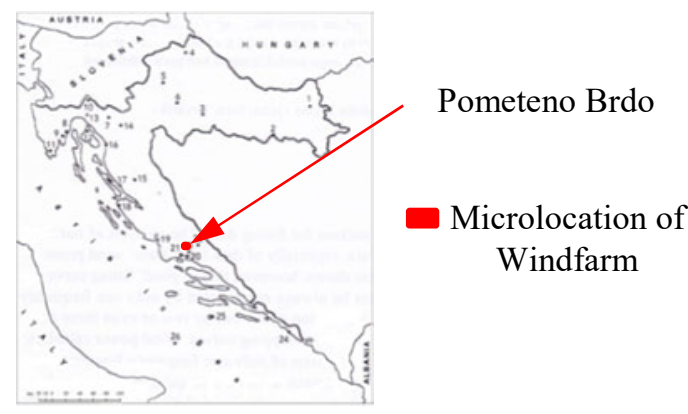

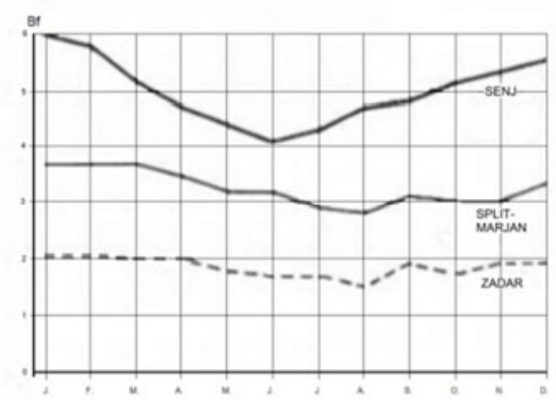

Fig. 2 Annual mean wind speeds in Beaufort of the most common Northeast wind at Senj, Split and Zadar from 1956 to 1965 [4]

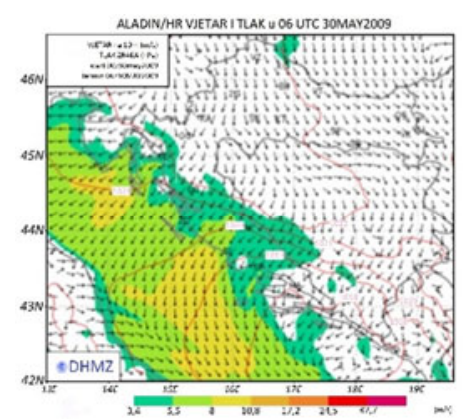

Fig. 3 Location of anemograph stations [5] and of wind turbines in coastal areas of Croatia
Fig. 4 Wind direction and wind power for a period of 6 hours on May 30, 2009 on the Croatian coast based on Aladin-Croatia

One of the vital components of a wind turbine is the axle pin (labelled 5 in Fig. 5)) that takes dynamic loads from rotor bearings and transmits them as flexural and shear loads to other parts of the wind turbine. The cross-section of a wind turbine presented in Fig. 5 shows the position of the axle pin. Axle pin of a wind turbine is the part that is exposed to dynamic flexural loads and to negligible dynamic shear loads [1]. Fatigue problems of metal materials 
have been also analysed [8-10]. The function of the axle pin is to carry the hub (labelled 3) with blades and other rotating parts. This is made possible with a single pair of bearing (labelled 4), that connect the hub to the axle pin.

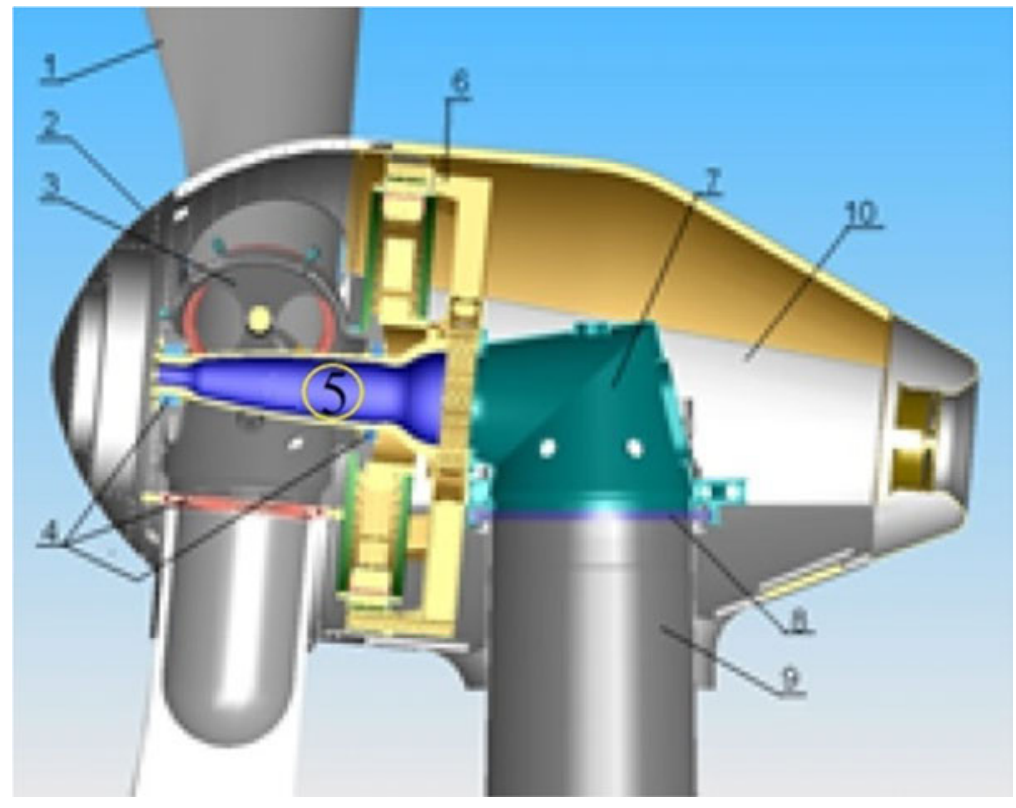

Fig. 5 Cross-section of a wind turbine with major components

The paper describes the procedure for assessing the impact of changes in wind speed at the height of the measured stresses on the axle pin. Also, it is shown that on the basis of the calculation model of wind obtained with the GH Bladed software, input data for the SolidWorks software are obtained, by which stresses on the axle pin are calculated.

\section{Measurement of strains on axle pin caused by wind loads}

Axle pin is made of cast steel material and is melted in an electric induction furnace. The properties of cast steel are improved by heat treatment, consisting of annealing, quenching and tempering. The mechanical properties are measured by a tensile test using standard specimens made of the remaining portion of the axle pin, which was removed after the mechanical treatment. Yield stress was higher than $\mathrm{R}_{\mathrm{p} 0,2}=539 \mathrm{MPa}$, tensile strength was greater than $\mathrm{R}_{\mathrm{m}}=590 \mathrm{MPa}$, with a modulus of elasticity $\mathrm{E}=210 \mathrm{GPa}$ and Poisson`s ratio $v=0,3$. Measurement of the wind speed at the location before installing the wind turbine prototype is always carried out on two measuring masts [11] and begins with the determination of necessary correlations between the measured values and wind speed data over year [11]. After the measurement, the second mast is replaced with the wind turbine prototype ${ }^{1}$, and then the results of the current/first measurement mast are used for the determination of characteristics [12-15] of the wind on the site of the wind turbine [16]. For the purposes of the mechanical calculation of the axle pin, the values of wind which are measured on the first mast and are not contaminated $[11,17,18]$ are used. To assess the impact of the wind on the load of the axle pin, measurements [19] were executed in periods of 6 seconds, (Fig. 6) and at the same time the deformations were also measured (Fig. 9, 10, 11). Increased frequency of signal recording is characteristic of these measurements.

\footnotetext{
${ }^{1}$ When the wind turbine is installed, turbulence at the top of the wind turbine on the location of the measuring device is induced, not ambient, and it is generally slightly increased.
} 


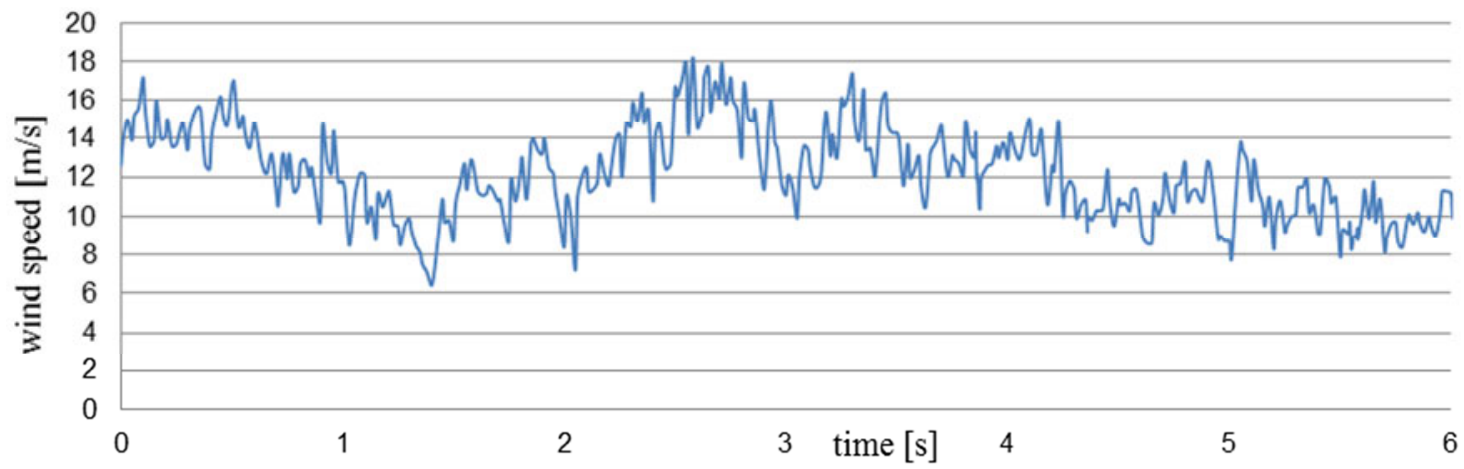

Fig. 6 Results of wind speed measurements

According to the theoretical calculations of stress as well as to the measurements, location $E$ is the most loaded portion of the axle pin. Since the axle pin is loaded in the material elastic range, the stresses are proportional to strains, according to Hook's law. Strains on the axle pin are measured by using strain gauge rosettes whose positions can be seen in Fig. 7. Wind speed data and data from the measuring rosettes are stored in the computer system for data collection. Data from the measuring rosette were obtained by sampling at $200 \mathrm{~Hz}$, while wind direction data were acquired by sampling at $50 \mathrm{~Hz}$.

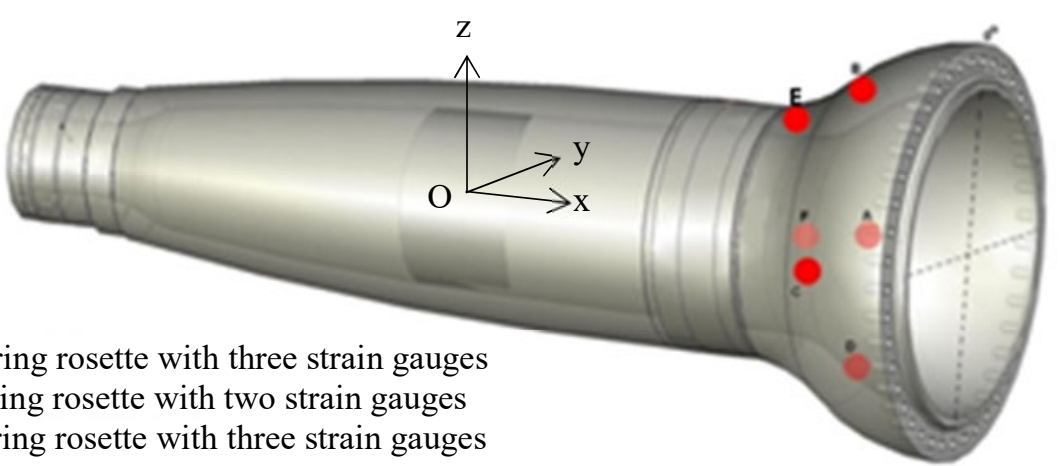

A,D - measuring rosette with three strain gauges

$\mathrm{B}, \mathrm{C}-$ measuring rosette with two strain gauges

$\mathrm{E}, \mathrm{F}$ - measuring rosette with three strain gauges

Fig. 7 Schematic representation of locations of measuring rosettes on the axle pin

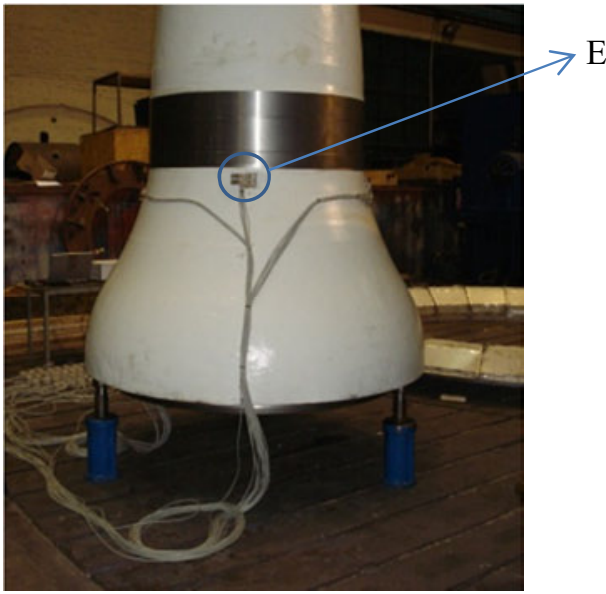

Fig. 8a Position of the measuring rosette on the axle pin (outside)

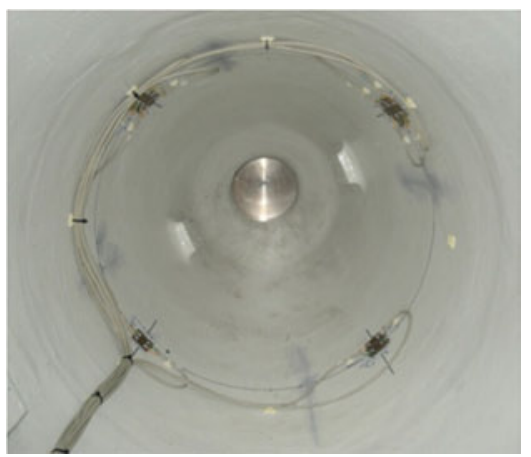

Fig. 8b Position of the measuring rosette on the axle pin (inside) 


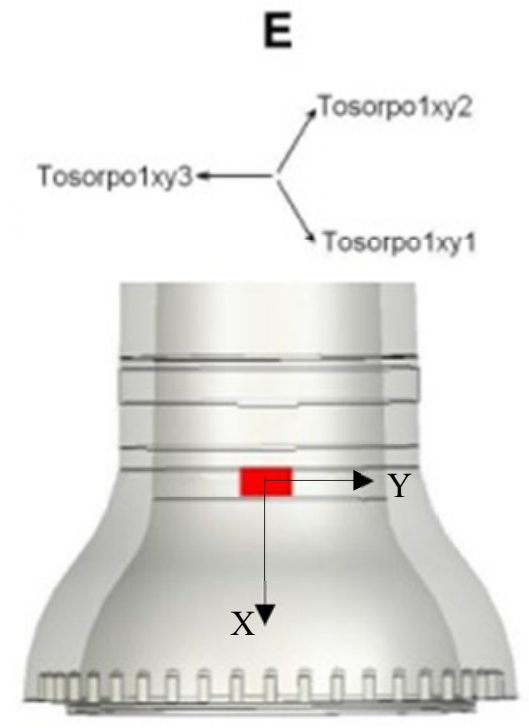

Fig. 8c Position of the measuring rosette $E$ and corresponding strain gauges

Figs. $8 \mathrm{a}, 8 \mathrm{~b}$ and $8 \mathrm{c}$ show positions of the measuring rosette. They correspond to the planned positions in the design. In Fig. 8c the position of the measuring rosette $E$ with its strain gauges is shown. Strain gauges have tags Tosorpolxy1, Tosorpo1xy2 and Tosorpo1xy3. The $\mathrm{x}$-axis represents the direction of the wind, while the $\mathrm{y}$-axis is on the same plane and is perpendicular to the $\mathrm{x}$-axis.

Figs. 9, 10 and 11 show values of stresses calculated for each strain gauge of the measuring rosette $E$.

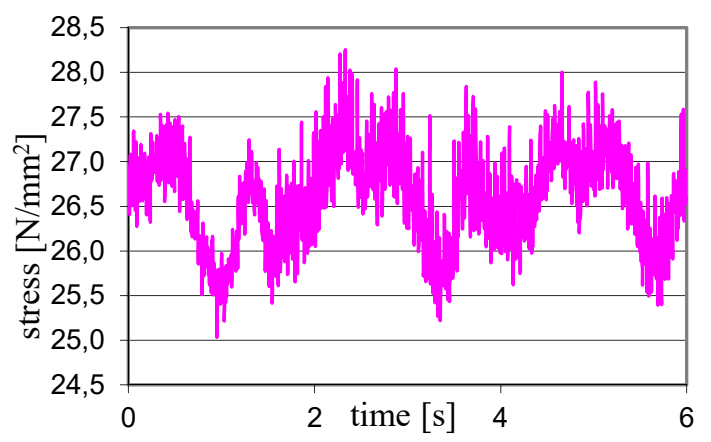

Fig. 9 Values of stresses on strain gauge Tosorpo1xy1 on measuring rosette $E$

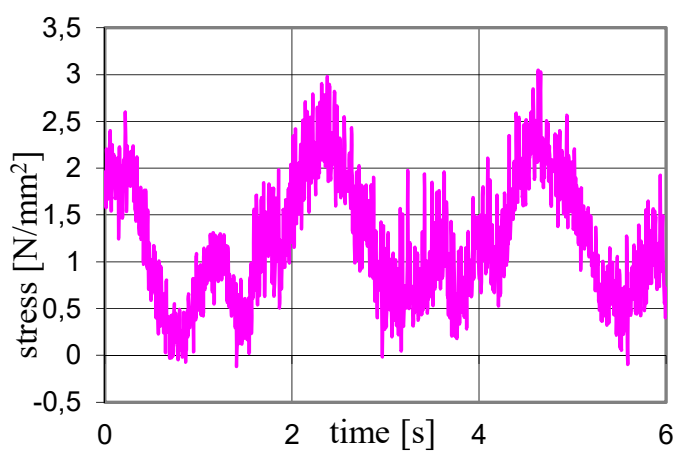

Fig. 10 Values of stresses on strain gauge Tosorpo1xy2 on measuring rosette $E$ 


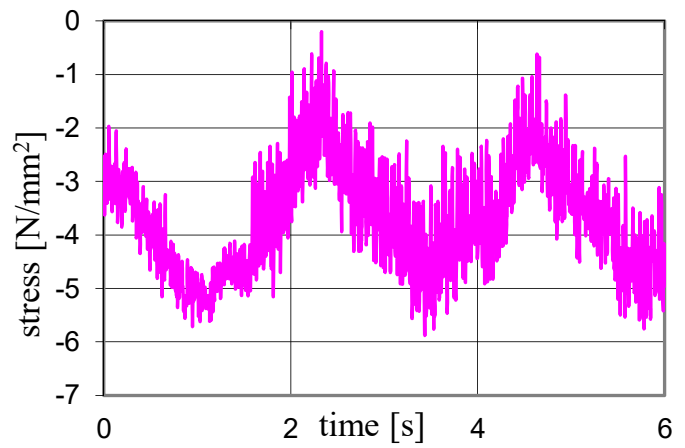

Fig. 11 Values of stresses on strain gauge Tosorpo1xy3 on measuring rosette $E$

Calculations of the main strain and stresses [20] and [21] are made on the basis of the results of measurements carried out with strain gauges of the measuring rosette $E$ (Figs. 9, 10 and 11).

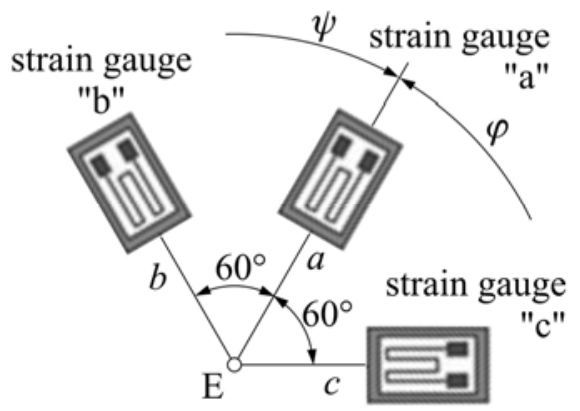

Fig. $120^{\circ} / 60^{\circ} / 120^{\circ}$ measuring rosette

Description of the strain gauges in the rosette is as follows:

- strain gauge $\boldsymbol{a}$ (Tosorpo1xy2) of measuring rosette $E$,

- strain gauge $\boldsymbol{b}$ (Tosorpo1xy1) of measuring rosette $E$ and

- $\quad$ strain gauge $c$ (Tosorpo1xy3) of measuring rosette $E$ (see Figs. 8c and 12).

The analytical solution of the $0^{\circ} / 60^{\circ} / 120^{\circ}$ measuring rosette is as follows:

- the principal strains $\varepsilon_{1}$ and $\varepsilon_{2}$, when measured with the strain gauge method, are calculated according to the expression ([20,21,22]):

$$
\varepsilon_{1,2}=\frac{\varepsilon_{a}+\varepsilon_{b}+\varepsilon_{c}}{3} \pm \frac{\sqrt{2}}{3} \sqrt{\left(\varepsilon_{a}-\varepsilon_{b}\right)^{2}+\left(\epsilon_{b}-\epsilon_{c}\right)^{2}+\left(\varepsilon_{c}-\varepsilon_{a}\right)^{2}}
$$

where $\varepsilon_{a}, \varepsilon_{b}, \varepsilon_{c}$ are strains of individual strain gauges,

- the principal stresses $\sigma_{1}$ and $\sigma_{2}$, and the directions of the principal stresses in the measuring point of the object are calculated based on the measured strains $\boldsymbol{\varepsilon}_{\boldsymbol{a}}, \boldsymbol{\varepsilon}_{\boldsymbol{b}}, \boldsymbol{\varepsilon}_{\boldsymbol{c}}$ in the directions $\boldsymbol{a}, \boldsymbol{b}, \boldsymbol{c}$ of the strain gauges of the used measuring rosette according to equations $([20,21,22])$ :

$$
\sigma_{1,2}=\frac{E}{1-\vartheta} \frac{\varepsilon_{a}+\varepsilon_{b}+\varepsilon_{c}}{3} \pm \frac{E}{1+\vartheta} \sqrt{\left(\frac{2 \cdot \varepsilon_{a}-\epsilon_{b}-\epsilon_{c}}{3}\right)^{2}+\frac{1}{3}\left(\epsilon_{b}-\epsilon_{c}\right)^{2}}
$$

or

$$
\sigma_{1}=\frac{E}{1+\vartheta}\left(\varepsilon_{1}+v \cdot \varepsilon_{2}\right) ; \quad \sigma_{2}=\frac{E}{1+\vartheta}\left(\varepsilon_{2}+v \cdot \varepsilon_{1}\right) ;
$$

the angle of the main direction of stress 1 to the corresponding strain gauge makes an angle $\psi$, which is calculated according to the formula: 


$$
\tan 2 \psi=\left|\frac{\sqrt{3 \cdot} \cdot\left(\varepsilon_{c}-\varepsilon_{b}\right)}{2 \cdot \varepsilon_{a}-\left(\varepsilon_{b}+\varepsilon_{c}\right)}\right|, \text { from which it follows } \psi \text {, and }
$$

the angle of the second principal direction 2 of stress $\varphi$ is calculated according to the angle $\psi$ as follows:

$$
\varphi=\psi-90^{\circ}
$$

The calculation results are as follows:

- the values of maximum principal strains are:

$$
\begin{aligned}
& \varepsilon_{1}=131.466 \cdot \mathrm{E} 10^{-6} \mathrm{~mm} / \mathrm{mm} \text { and } \\
& \varepsilon_{2}=-5.766 \cdot \mathrm{E} 10^{-6} \mathrm{~mm} / \mathrm{mm}, \text { while } \\
& \psi=33.63^{\circ} .
\end{aligned}
$$

- the values of maximum principal stresses are:

$$
\begin{aligned}
& \sigma_{I}=27.423 \mathrm{~N} / \mathrm{mm}^{2} \text { and } \\
& \sigma_{2}=-0.29527 \mathrm{~N} / \mathrm{mm}^{2} .
\end{aligned}
$$

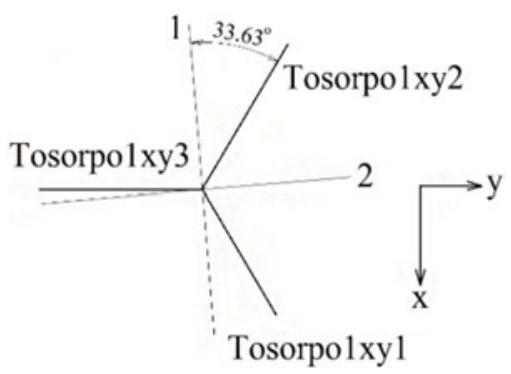

Fig. 13 Principal directions of stresses and strains 1 and 2 at measuring point $E$

The position of principal stresses at the point $E$ is shown in Fig. 13. The deviation of the strain gauge $\boldsymbol{a}$ is $33.63^{\circ}$, and the deviation of the direction of the wind (the x-axis) is $3.63^{\circ}$.

\section{Determination of bearing load}

Simulation tools for the design of wind turbines are only an analytical type of software. One such tool is the GH Bladed software [23]. It presents the structure of a wind turbine as a series of discrete points with the necessary characteristics of the wind turbine. As an incentive, the model of wind is set in the GH Bladed software, which is presented with a series of discrete points in which speed, wind direction and time are defined. Using the socalled elementary theory of blades [24] and [25] from a given excitation wind, the torque moment is calculated, which causes rotation of the rotor and the downforce on the rotor in the defined points of the rotor. With the usage of the so-called modal analysis, a response model of the structure is then calculated, so as to obtain forces and moments in the predefined points of construction. The analytical GH Bladed software is not familiar with the concept of stress. The concept of stress is exclusively associated with numerical programs. The mechanical components of the wind turbine are designed by applying numerical software packages that allow the calculation of the stress of the structure. The numerical software package used in this study is SolidWorks.

The necessary forces and moments from the analytical GH Bladed software are input values for the numerical SolidWorks software. GH Bladed determines the force, torque and acceleration in discrete points. On the axle pin the discrete point is the intersection of two axes. The first axis is the axis of the axle pin and the second axis is the axis of the blades (Fig. 14). 


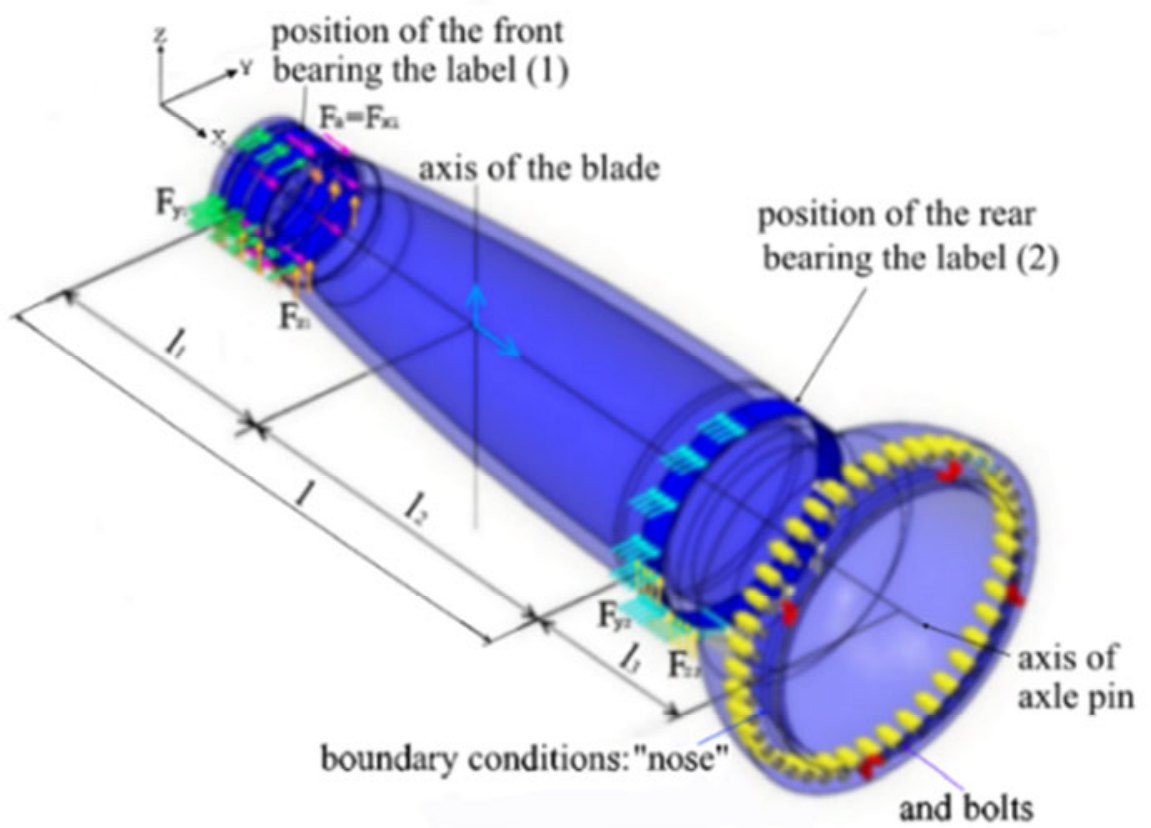

Fig. 14 Axle pin with elements for calculation

That point is determined by torques, forces and accelerations in all three axes $\left(M_{x}, M_{y}\right.$, $\left.M_{z}, F_{x}, F_{y}, F_{z}, a_{x}, a_{y}, a_{z}, \varepsilon_{x}, \varepsilon_{y}, \varepsilon_{z}\right)$. To determine the load on the bearings an additional routine was used, which we apply in GH Bladed, in the section called 'channel combination'. The routine is defined by the values of the discrete points, the geometry presented in Fig. 14 and the equations of mechanics [26] for carriers with two supports and overhang. On the bearings, the following action forces are obtained: $F_{x 1}, F_{Y 1}, F_{Z 1}, F_{r l}, F_{Y 2}, F_{z 2}, F_{r}$ (Table 1).

The front bearing (labelled 1) takes the radial and axial forces, while the rear bearing (labelled 2) takes the radial force (Fig. 14, Table 1). Distance $l_{l}$ represents the distance from the axis of the blade to the axis of the front bearing, distance $l_{2}$ is the distance from the axis of the blade to the back bearing, $l$ is the distance between the bearings, and $l_{3}$ is the distance between the rear bearing and the axis of the generator (Fig. 14). In the analysis of the boundary conditions, the bolts and the "nose" were included (Fig. 14). The bolts prevent movement in the longitudinal direction, and the "nose" (Fig. 14) prevents movement in the radial and circular direction. The "nose" holds the axle pin and is mathematically treated as a plan bearing. The "nose" resists the component load at half of its circumference. From a range of design load cases, one combination of loads has been taken (Table 1).

Table 1 Cases of design load on axle pin bearings

\begin{tabular}{|c|c|c|c|c|c|c|}
\hline$F_{\mathrm{x} 1}=F_{\mathrm{a}}$ & $F_{\mathrm{y} 1}$ & $F_{\mathrm{z} 1}$ & $F_{\mathrm{r} 1}$ & $F_{\mathrm{y} 2}$ & $F_{\mathrm{z} 2}$ & $F_{\mathrm{r} 2}$ \\
\hline $\mathrm{kN}$ & $\mathrm{kN}$ & $\mathrm{kN}$ & $\mathrm{kN}$ & $\mathrm{kN}$ & $\mathrm{kN}$ & $\mathrm{kN}$ \\
\hline 38.1 & 2194.0 & 757.4 & 2321.0 & -1534.4 & -696.8 & 1685.2 \\
\hline
\end{tabular}

As a rule, because of load distribution, reactions at the "nose" appear on the $3 / 4$ of the circumference of the "nose". On the basis of these loads a calculation was performed by applying the finite elements method. The calculated results are used for the analysis of stresses at point $E$. To achieve high precision, it is necessary to determine the plane and a point at which we want to determine stress and stress components (Fig. 15). 


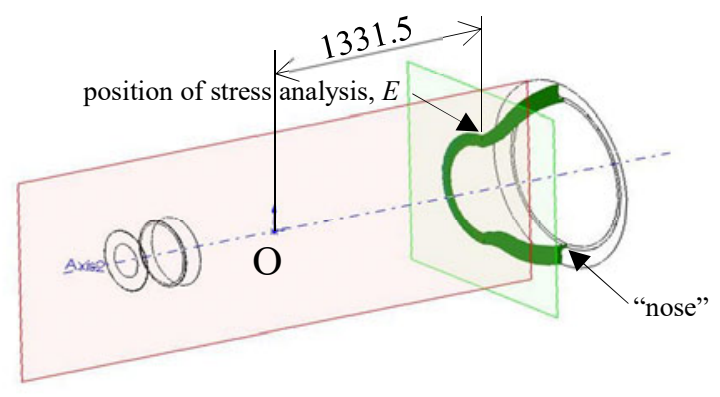

Fig. 15 The planes (longitudinal and transverse) that define the place of analysis of point $E$

In the field of elastic strain/calculated stress, the relationship of forces and stresses at the some point in the structure can be determined by the equation:

$$
\sigma=k \sigma \cdot F
$$

where $\sigma$ is the stress and the product of the coefficient of stress $k \sigma$ and force $F$. The above equation (6) written for one component of the stress is as follows:

$$
\left(\sigma_{x x}\right)_{x 1}=(k \sigma)_{x 1} \cdot F_{x 1}
$$

where $\left(\sigma_{x x}\right)_{x l}$ is the stress in the x-axis direction and the product of the coefficient of stress $(k \sigma)_{x l}$ and axial force $F_{x l}$. Table 2 gives an overview of all the components of loads and stresses, while Table 3 gives an overview of all the load components and coefficients of stresses. Thus a relationship between the analytical and the numerical software is established.

The stress will be read at the highest point of intersection. That point is $1331.5 \mathrm{~mm}$ away from the intersection of two axes. One axis is the blade axis and another is the axle pin axis (Figs. 14 and 15). This is a cross-section where measuring rosette $E$ is placed (Figs. 7, 8c and 15).

For the purposes of the FEM analysis high quality solid continuum is used, as well as the quadratic tetrahedral element with three degrees of freedom at each of ten nodes (Fig. 16).

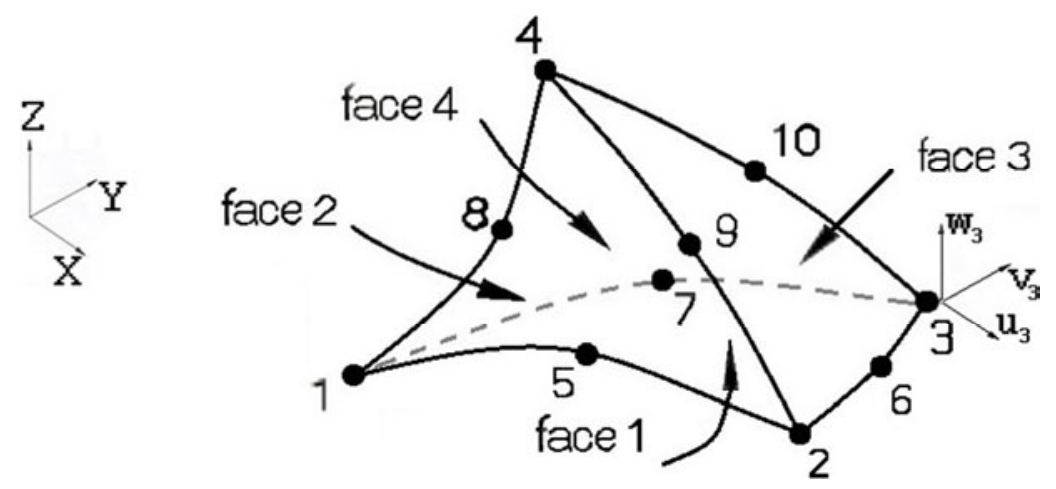

Fig. 16 Finite elements, the ten node tetrahedron [27]

Degrees of freedom of the tetrahedral finite element can be described by:

$$
\mathrm{v}^{T}=\left[u_{1}, v_{1}, w_{1}, u_{2}, v_{2}, w_{2}, \ldots \ldots u_{i}, v_{i}, w_{i}, \ldots . u_{10}, v_{10}, w_{10}\right]
$$

Displacements in the element are described with a complete second order polynomial:

$$
\begin{aligned}
& u=a_{1}+a_{2} \cdot x+a_{3} \cdot y+a_{4} \cdot z+a_{5} \cdot x^{2}+a_{6} \cdot y^{2}+a_{7} \cdot z^{2}+a_{8} \cdot x y+a_{9} \cdot y z+a_{10} \cdot x z \\
& v=a_{11}+a_{12} \cdot x+a_{13} \cdot y+a_{14} \cdot z+a_{15} \cdot x^{2}+a_{16} \cdot y^{2}+a_{17} \cdot z^{2}+a_{18} \cdot x y+a_{19} \cdot y z+a_{20} \cdot x z \\
& w=a_{21}+a_{22} \cdot x+a_{23} \cdot y+a_{24} \cdot z+a_{25} \cdot x^{2}+a_{26} \cdot y^{2}+a_{27} \cdot z^{2}+a_{28} \cdot x y+a_{29} \cdot y z+a_{30} \cdot x z
\end{aligned}
$$


where $a_{1}$ to $a_{30}$ are approximation coefficients of the finite element. With the introduction of the coordinates' position of the node and corresponding displacements, the coefficients can be expressed by displacements in the nodes, which are obtained in SolidWorks.

In this element one of the conditions for convergence solutions is satisfied. The field of strains is described with the function of the second degree (9). Since it is a function that describes the distribution of strain and stress of a lower order of the function allocation displacements, i.e. the tetrahedral finite element, the second degree of function can describe the linear strain and stress filed.

By changing the size of the finite elements (Fig. 17) and by applying the method of convergence [27] different values of stresses were obtained. One of the tools that can assist in this process is adaptive meshing, which is a tool used to iteratively vary the mesh settings for a model without an active user's intervention. SolidWorks Simulation uses two different methods to accomplish h-adaptive and p-adaptive meshing.

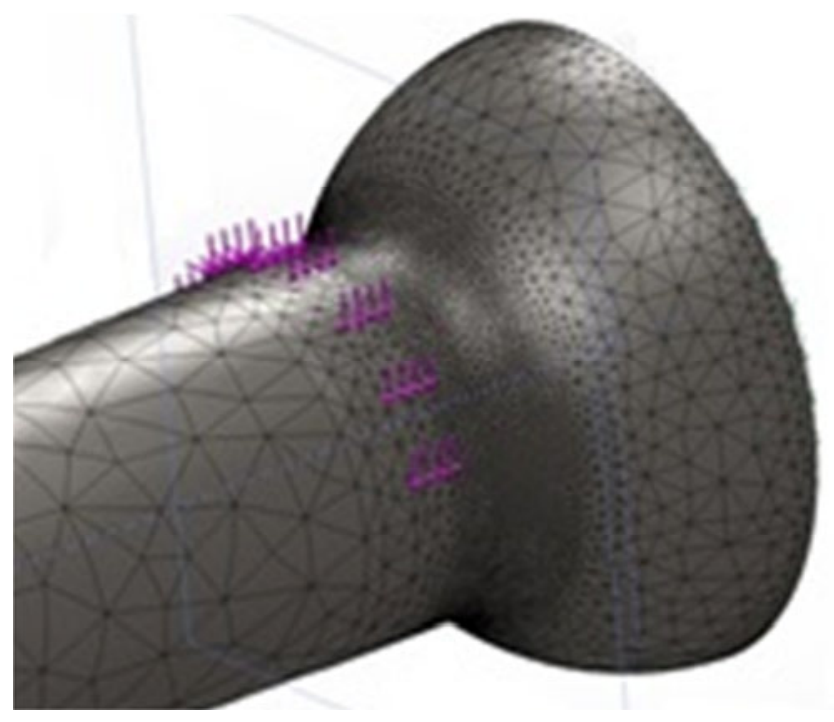

Fig.17 The mesh of finite elements with the press-fit surface under axial bearing

$\mathrm{H}$-adaptive meshing physically adjusts the size of the mesh cell in areas of the model where smaller mesh is needed. This is all done automatically by the software based on desired accuracy defined by the user. The software achieves the target accuracy by measuring the change in strain energy and stops iterations when two consecutive values differ by less than the given value.

Table 2 Stresses obtained by loads from Table 1

\begin{tabular}{|c|c|c|c|c|c|c|}
\cline { 2 - 7 } & \multicolumn{1}{c|}{$\begin{array}{c}\sigma_{\mathrm{xx}} \\
\mathrm{N} / \mathrm{mm}^{2}\end{array}$} & $\begin{array}{c}\sigma_{\mathrm{yy}} \\
\mathrm{N} / \mathrm{mm}^{2}\end{array}$ & $\begin{array}{c}\sigma_{\mathrm{zz}} \\
\mathrm{N} / \mathrm{mm}^{2}\end{array}$ & $\begin{array}{c}\tau_{\mathrm{xy}} \\
\mathrm{N} / \mathrm{mm}^{2}\end{array}$ & $\begin{array}{c}\tau_{\mathrm{zx}} \\
\mathrm{N} / \mathrm{mm}^{2}\end{array}$ & $\begin{array}{c}\tau_{\mathrm{yz}} \\
\mathrm{N} / \mathrm{mm}^{2}\end{array}$ \\
\cline { 2 - 8 } Toads & -127.92 & -3.94 & -55.7 & -20.63 & -21.73 & -2.88 \\
\hline$F_{\mathrm{x} 1}=+38.1 \mathrm{kN}$ & -0.50 & -0.02 & -0.22 & -0.08 & -0.002 & -0.0002 \\
\hline$F_{\mathrm{y} 1}=+2194.0 \mathrm{kN}$ & -2.48 & -0.16 & -3.18 & -0.047 & -6.28 & -0.7 \\
\hline$F_{\mathrm{z} 1}=+757.4 \mathrm{kN}$ & -137.18 & -4.42 & -56.82 & -22.01 & -0.41 & 0.06 \\
\hline$F_{\mathrm{y} 2}=-1534.4 \mathrm{kN}$ & -4.21 & -0.05 & 3.41 & -0.73 & -15.41 & -2.48 \\
\hline$F_{\mathrm{z} 2}=-696.8 \mathrm{kN}$ & 18.79 & 0.71 & 1.09 & 3.02 & 0.09 & 0.001 \\
\hline \hline Total & -125.57 & -3.94 & -55.73 & -20.26 & -22.00 & -2.49 \\
\hline \hline Deviation $(\%)$ & 1.84 & 0.03 & -0.04 & 1.74 & -1.25 & 1.21 \\
\hline
\end{tabular}


For additional control of the precision of the results the method of superposition is used [28], (Table 2). In Table 2, stresses by components are presented, for total load and for each force individually. The last row of Table 2 shows deviation of the sum of individual stress loads and total load. The method of superposition is used for application in the analytic software. Table 3 presents the loads and coefficients of stress. When the loads from Table 3 are multiplied with the coefficients from the same table, the product is equal to the corresponding elements of the stress from Table 2.

Table 3 Coefficients of stress

\begin{tabular}{|c||c|c|c|c|c|c|}
\hline & $\begin{array}{c}\mathrm{k} \sigma_{\mathrm{xx}} \\
1 / \mathrm{mm}^{2}\end{array}$ & $\begin{array}{c}\mathrm{k} \sigma_{\mathrm{yy}} \\
1 / \mathrm{mm}^{2}\end{array}$ & $\begin{array}{c}\mathrm{k} \sigma_{\mathrm{zz}} \\
1 / \mathrm{mm}^{2}\end{array}$ & $\begin{array}{c}\mathrm{k} \tau_{\mathrm{xy}} \\
1 / \mathrm{mm}^{2}\end{array}$ & $\begin{array}{c}\mathrm{k} \tau_{\mathrm{zx}} \\
1 / \mathrm{mm}^{2}\end{array}$ & $\begin{array}{c}\mathrm{k} \tau_{\mathrm{yz}} \\
1 / \mathrm{mm}^{2}\end{array}$ \\
\hline \hline$F_{\mathrm{x} 1}=+38.1 \mathrm{kN}$ & $-1.31 \mathrm{E}-05$ & $-3.94 \mathrm{E}-07$ & $-5.87 \mathrm{E}-06$ & $-2.17 \mathrm{E}-06$ & $-7.01 \mathrm{E}-08$ & $-4.2 \mathrm{E}-09$ \\
\hline$F_{\mathrm{y} 1}=+2194.0 \mathrm{kN}$ & $-1.13 \mathrm{E}-06$ & $-7.41 \mathrm{E}-08$ & $-1.45 \mathrm{E}-06$ & $-2.13 \mathrm{E}-07$ & $-2.86 \mathrm{E}-06$ & $-3.2 \mathrm{E}-07$ \\
\hline$F_{\mathrm{z} 1}=+757.4 \mathrm{kN}$ & $-1.81 \mathrm{E}-4$ & $-5.83 \mathrm{E}-06$ & $-7.50 \mathrm{E}-05$ & $-2.91 \mathrm{E}-05$ & $-5.37 \mathrm{E}-07$ & $8.49 \mathrm{E}-08$ \\
\hline$F_{\mathrm{y} 2}=-1534.4 \mathrm{kN}$ & $2.74 \mathrm{E}-06$ & $3.22 \mathrm{E}-08$ & $-2.22 \mathrm{E}-06$ & $4.74 \mathrm{E}-07$ & $1.004 \mathrm{E}-05$ & $1.62 \mathrm{E}-06$ \\
\hline$F_{\mathrm{z} 2}=-696.8 \mathrm{kN}$ & $-2.69 \mathrm{E}-05$ & $-1.02 \mathrm{E}-06$ & $-1.56 \mathrm{E}-06$ & $-4.34 \mathrm{E}-06$ & $-1.34 \mathrm{E}-07$ & $-1.89 \mathrm{E}-09$ \\
\hline
\end{tabular}

\section{The calculation of stresses with actual wind}

Once all the necessary data on the wind turbine are entered into GH Bladed [23], the measured wind data are entered into the post/processing function PowerProductionLoading.

Table 4 Input data of wind

\begin{tabular}{|c||c|c|c|c|c|c|c|c|c|c|c|c|}
\hline position & 1 & 2 & 3 & 4 & 5 & 6 & 7 & 8 & 9 & 10 & 14 & 100 \\
\hline time/ sec & 0 & 0.04 & 0.14 & 0.17 & 0.24 & 0.31 & 0.37 & 0.44 & 0.51 & 0.57 & $\ldots$ & 6.0 \\
\hline wind/ m/s & 12.6 & 14.5 & 15.48 & 14.5 & 14.1 & 14.5 & 14.08 & 15.28 & 15.75 & 14.45 & $\ldots$ & 10.25 \\
\hline rel. direct./ $^{\circ}$ & 0 & 0 & 0 & 0 & 0 & 0 & 0 & 0.008 & 0.04 & 0.09 & $\ldots$ & 10.38 \\
\hline
\end{tabular}

Wind data from Table 4 are average values for some period of time. Table 4 shows the set of wind data that is needed for the calculation. It consists of time of measurement, wind speed and relative wind angle. Based on the data from Table 4 loads acting on the bearings of the axle pin were obtained and are shown in Table 5. Table 5 gives also combinations of forces. One such load combination gives the maximum principal stress. Using Table 3 and Table 5 the results of the stresses were obtained and are presented in Table 6. Equivalent stress is determined by the half-maximum height $(\mathrm{HMH})$ method $[27,28]$, in accordance with the equation:

$$
\sigma_{e k v}=\sqrt{\frac{\left(\sigma_{x x}-\sigma_{x x}\right)^{2}+\left(\sigma_{x x}-\sigma_{x x}\right)^{2}+\left(\sigma_{x x}-\sigma_{x x}\right)^{2}+6 \cdot\left(\tau_{x y}^{2}+\tau_{y z}^{2}+\tau_{z x}^{2}\right)}{2}}
$$


Table 5 Ultimate loads in press-fit surface under axial bearing at axle pin

\begin{tabular}{|l||c||c|c|c|c|c|c|c|c|c|}
\hline & & & $F_{\mathrm{x} 1}$ & $F_{\mathrm{y} 1}$ & $F_{\mathrm{z} 1}$ & $F_{\mathrm{r} 1}$ & $F_{\mathrm{y} 2}$ & $F_{\mathrm{z} 2}$ & $F_{\mathrm{r} 2}$ & Correlation factor \\
\hline \hline & & Load case & $\mathrm{kN}$ & $\mathrm{kN}$ & $\mathrm{kN}$ & $\mathrm{kN}$ & $\mathrm{kN}$ & $\mathrm{kN}$ & $\mathrm{kN}$ & - \\
\hline$F_{\mathrm{x} 1}$ & Max & powprod & 143.5 & -30.6 & -93.5 & 98.4 & 42.6 & -241.2 & 244.9 & 1.00 \\
\hline$F_{\mathrm{x} 1}$ & Min & powprod & 140.0 & 0.32 & -143.0 & 143.0 & 6.86 & -227.2 & 227.3 & 1.00 \\
\hline$F_{\mathrm{y} 1}$ & Max & powprod & 133.3 & 3.20 & -91.5 & 91.6 & 5.29 & -248.9 & 248.9 & 1.00 \\
\hline$F_{\mathrm{y} 1}$ & Min & powprod & 126.6 & -42.0 & -80.0 & 90.4 & 52.5 & -257.9 & 263.2 & 1.00 \\
\hline$F_{\mathrm{z} 1}$ & Max & powprod & 139.2 & -28.3 & -50.5 & 57.9 & 40.7 & -285.3 & 288.2 & 1.00 \\
\hline$F_{\mathrm{z} 1}$ & Min & powprod & 147.7 & 0.44 & -121.0 & 121.0 & 5.28 & -219.6 & 219.7 & 1.00 \\
\hline$F_{\mathrm{r} 1}$ & Max & powprod & 147.7 & 0.44 & -121.0 & 121.0 & 5.28 & -219.6 & 219.7 & 1.00 \\
\hline$F_{\mathrm{r} 1}$ & Min & powprod & 136.8 & -25.5 & -51.0 & 57.0 & 37.2 & -286.7 & 289.1 & 1.00 \\
\hline$F_{\mathrm{y} 2}$ & Max & powprod & 128.2 & -41.6 & -85.6 & 95.1 & 52.6 & -252.5 & 257.9 & 1.00 \\
\hline$F_{\mathrm{y} 2}$ & Min & powprod & 134.5 & 1.47 & -106.4 & 106.4 & 3.35 & -234.7 & 234.8 & 1.00 \\
\hline$F_{\mathrm{z} 2}$ & Max & powprod & 147.7 & 0.44 & -121.0 & 121.0 & 5.28 & -219.6 & 219.7 & 1.00 \\
\hline$F_{\mathrm{z} 2}$ & Min & powprod & 136.1 & -26.0 & -51.2 & 57.4 & 34.0 & -286.7 & 288.7 & 1.00 \\
\hline$F_{\mathrm{r} 2}$ & Max & powprod & 136.8 & -25.5 & -51.0 & 57.0 & 37.2 & -286.7 & 289.1 & 1.00 \\
\hline$F_{\mathrm{r} 2}$ & Min & powprod & 147.7 & 0.44 & -121.0 & 121.0 & 5.28 & -219.6 & 219.7 & 1.00 \\
\hline
\end{tabular}

Table 6 presents values of the stress components, equivalent stresses and principal stresses. Field measurements were taken to measure characteristics of the wind with the degree of turbulence of 6.73 and turbulence intensity of $1.23 \%$. The results of the field measurements are shown in Figs. 6, 9, 10 and 11. According to the Wind diagram (Fig. 6) and stress images (Figs. 9, 10 and 11) the stress signal lags behind the drive signal of the wind, which is a characteristic of dynamic phenomena. The study provides justification for the application as well as accuracy of the mathematical model of loading components obtained by GH Bladed. The present method of determining the coefficient of stresses is applicable to any type of structural elements.

Table 6 Components of stresses at point $E$ in the design load case named powprod

\begin{tabular}{|c||c||c|c|c|c|c|c|c|c|c|c|}
\hline & & $\sigma_{\mathrm{xx}}$ & $\sigma_{\mathrm{yy}}$ & $\sigma_{\mathrm{zz}}$ & $\tau_{\mathrm{xy}}$ & $\tau_{\mathrm{yz}}$ & $\tau_{\mathrm{zx}}$ & $\sigma_{\mathrm{ekv}}$ & $\sigma_{1}$ & $\sigma_{2}$ & $\sigma_{3}$ \\
\hline \hline & & $\mathrm{N} / \mathrm{mm}^{2}$ & $\mathrm{~N} / \mathrm{mm}^{2}$ & $\mathrm{~N} / \mathrm{mm}^{2}$ & $\mathrm{~N} / \mathrm{mm}^{2}$ & $\mathrm{~N} / \mathrm{mm}^{2}$ & $\mathrm{~N} / \mathrm{mm}^{2}$ & $\mathrm{~N} / \mathrm{mm}^{2}$ & $\mathrm{~N} / \mathrm{mm}^{2}$ & $\mathrm{~N} / \mathrm{mm}^{2}$ & $\mathrm{~N} / \mathrm{mm}^{2}$ \\
\hline \hline$F_{\mathrm{x} 1}$ & Max & 20.39 & 0.62 & 7.06 & 3.15 & 0.14 & 0.94 & 18.37 & 20.95 & 7.0 & 0.13 \\
\hline$F_{\mathrm{x} 1}$ & $\operatorname{Min}$ & 25.57 & 0.79 & 8.39 & 4.24 & 0.02 & 0.16 & 23.18 & 26.28 & 8.39 & 0.09 \\
\hline$F_{\mathrm{y} 1}$ & $\operatorname{Max}$ & 21.59 & 0.67 & 6.55 & 3.42 & 0.03 & 0.20 & 19.62 & 22.14 & 6.54 & 0.12 \\
\hline$F_{\mathrm{y} 1}$ & $\operatorname{Min}$ & 19.61 & 0.66 & 5.69 & 3.14 & 0.09 & 0.74 & 17.9 & 20.16 & 5.66 & 0.15 \\
\hline$F_{\mathrm{z} 1}$ & $\operatorname{Max}$ & 14.85 & 0.43 & 3.39 & 2.54 & 0.07 & 0.54 & 13.95 & 15.32 & 3.37 & -0.01 \\
\hline$F_{\mathrm{z} 1}$ & $\operatorname{Min}$ & 26.41 & 0.88 & 8.84 & 4.25 & 0.01 & 0.15 & 23.8 & 27.102 & 8.84 & 0.19 \\
\hline$F_{\mathrm{r} 1}$ & $\operatorname{Max}$ & 26.41 & 0.88 & 8.84 & 4.25 & 0.01 & 0.15 & 23.8 & 27.102 & 8.84 & 0.19 \\
\hline$F_{\mathrm{r} 1}$ & $\operatorname{Min}$ & 15.14 & 0.53 & 3.54 & 2.44 & 0.07 & 0.51 & 14.05 & 15.57 & 3.52 & 0.13 \\
\hline$F_{\mathrm{y} 2}$ & $\operatorname{Max}$ & 20.60 & 0.70 & 6.18 & 3.31 & 0.14 & 0.73 & 18.76 & 21.18 & 6.14 & 0.16 \\
\hline$F_{\mathrm{y} 2}$ & $\operatorname{Min}$ & 23.95 & 0.81 & 7.66 & 3.85 & 0.01 & 0.14 & 21.66 & 24.58 & 7.66 & 0.18 \\
\hline$F_{\mathrm{z} 2}$ & Max & 26.41 & 0.88 & 8.84 & 4.25 & 0.01 & 0.15 & 23.8 & 27.1 & 8.84 & 0.19 \\
\hline$F_{\mathrm{z} 2}$ & $\operatorname{Min}$ & 15.21 & 0.53 & 3.56 & 2.44 & 0.07 & 0.48 & 14.1 & 15.62 & 3.54 & 0.13 \\
\hline$F_{\mathrm{r} 2}$ & Max & 15.14 & 0.53 & 3.54 & 2.44 & 0.07 & 0.51 & 14.05 & 15.57 & 3.51 & 0.13 \\
\hline$F_{\mathrm{r} 2}$ & $\operatorname{Min}$ & 26.41 & 0.88 & 8.84 & 4.25 & 0.01 & 0.15 & 23.8 & 27.1 & 8.84 & 0.19 \\
\hline
\end{tabular}


The implementation of the method takes little time as opposed to the creation of analytical equations that describe the state of stress of complex structural elements. Finally, the coefficients of stress in Table 3 are valid only for one form of the structural element and one point on the structural element.

In this paper, in order to improve the convergence of the results and thus to improve the accuracy of the obtained values, the size of the finite element was changed according to [27]. The mesh is created with Curvature-Based Mesh ${ }^{2}$ and with Mesh Control ${ }^{3}$ in the area of point $E$. Element size is $72.31 \mathrm{~mm}$ and the tolerance is $2.47 \mathrm{~mm}$. In area $E$, at the point of determining the stress, the finite element size is 8.23 . Total number of nodes is 60878 and total number of elements is 34542 .

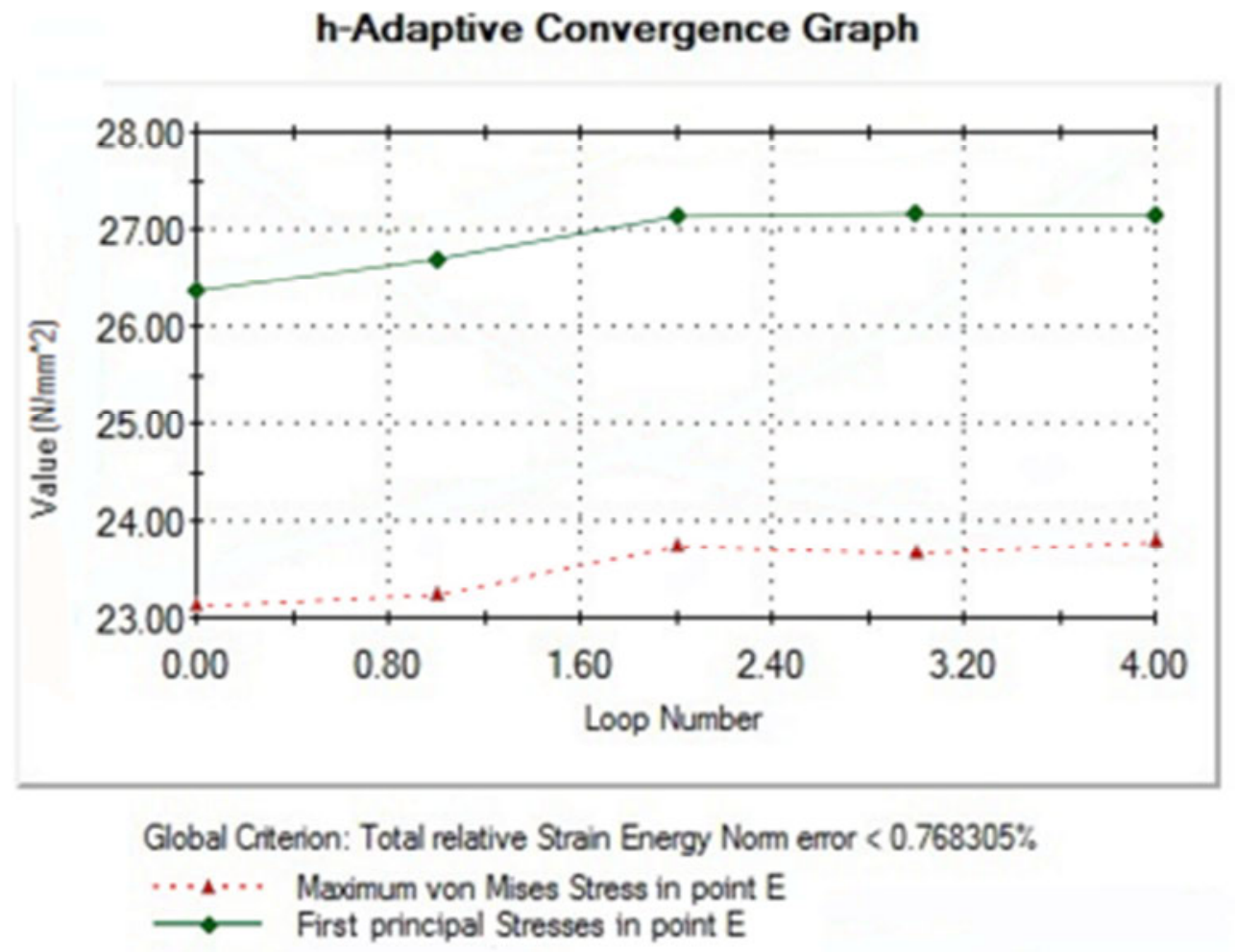

Fig. 18 Stresses in position $E$

With the use of the H-method and five iterations, converging values of stress (Fig. 18) are obtained. The deviation is less than $0.768 \%$. The results of the stress are given in the node. At the mesh of finite elements, there are no distorted elements.

\section{Discussion and conclusion}

Even when the power and direction of wind are known, wind turbine design is a challenge, as exact knowledge of the deformation of vital components caused by gusts of wind can be obtained only by performing measurements on the wind turbine, when the turbine is already installed and in operation. One of the vital components of the wind turbine is axle pin which takes dynamic loads of the rotor from bearings and transmits them as flexural and shear loads to other parts of the wind turbine. Final machining of the axle pin should be performed in a machine shop equipped with a force vs. displacement controller

\footnotetext{
${ }^{2}$ Activates the curvature-based meshing scheme for subsequent meshing operations. The mesher creates more elements in higher-curvature areas automatically.

${ }^{3}$ Mesh Control defined the mesh (smallest mesh element size in local area).
} 
system [29]. The axle pin as the most vital part of the wind turbine should be machined by applying a low feed and depth of cut, as reported in [30], in order to ensure low roughness of the machined surface. The best surface quality was achieved when the axle pin was fixed as a rigid body in the machining centre, as reported in [31,32].

This paper discusses the evaluation of the conformity between the calculated stress and the measured strains on the critical part of the axle pin and the loads are calculated with the GH Bladed software.

Measurements of wind speed and stresses shown that the maximum principal stress (filtered without peak) measured with a measuring rosette was $27.4 \mathrm{~N} / \mathrm{mm}^{2}$. The maximum calculated principal stress is $27.1 \mathrm{~N} / \mathrm{mm}^{2}$. The criterion of deviation is a comparison between the maximum calculated principal stresses and the obtained stresses. The difference between these two is $1.16 \%$. Because of the relatively small numbers, the minimum principal stresses are not analysed. The angle of the principal stress from strain gauge $\boldsymbol{a}$ of the measuring rosette has a deflection of $33.63^{\circ}$. It represents the angular offset of $3.63^{\circ}$ from the direction ${ }^{4}$ of the wind (x-axis). It leads to the conclusion that this state of stress tends to be uniaxial stress state.

Stresses with different load correlation coefficients were analysed. The best stress matching results are obtained with the correlation coefficient of 1.0. It stands for the windforce-stress ratio on the axle pin at a point of the measuring rosette $E$ according to Fig. 8 .

The measurements also showed that within only 6 seconds when wind speed changes from 6 to $18 \mathrm{~m} / \mathrm{s}$ there was a change in the load at the measuring point $E$ of the axle pin from 25 to $28 \mathrm{MPa}$. Such short-term measurements provide a better base for the required analysis. They are more convenient than long-term measurements, since the frequency of the record is several times higher within the current time interval.

As a link between analytical and numerical software "in-between software" probably will be used in future, a type of "generator" itself, based on the position/coordinates of the points $(\mathrm{x}, \mathrm{y}, \mathrm{z})$ which will provide necessary information about stresses. Perhaps only further development in and production of sophisticated computer software packages (which would include automatic transfer of data between different analytical and numerical software) enable its inclusion in the design process. It is particularly important to give clear instructions for the preparation of local models with a fine mesh of finite elements, because the resulting stresses are highly sensitive to the size and shape of the finite elements in the vicinity of a measuring point. In our case it is point $\mathrm{E}$. It is in the vicinity of the press-fit zone of the axial bearing.

\section{REFERENCES}

[1] M. Cvetić, I. Cukor, N. Gubeljak, J. Predan, A. Poleš: Design structural elements wind power in order to prevent breakage, 9th HRO CIGRE, Cavtat $8^{\text {th }}-12^{\text {th }}$, November 2009.

[2] Božić, Ž., Schmauder, S., Mlikota, M. and Hummel, M. (2014) Multiscale fatigue crack growth modelling for welded stiffened panels. Fatigue \& Fracture of Engineering Materials \& Structures, 37(9), 1043-1054. DOI: 10.1111/ffe.12189

[3] D. Poje: Bura (bora) and burin at Split, Croatian meteorological journal, 30, pp. 1-19, 1995.

[4] M.M. Yoshino: Studies on bora, AMAZON Book Review, Tokyo 1972.

\footnotetext{
${ }^{4}$ Later it has been found that the rosette on the length of $15 \mathrm{~mm}$ had has deflection from 1 to $1.5 \mathrm{~mm}$. This represents the angle variation in the range from $3.81^{\circ}$ to $5.71^{\circ}$. The influence of angle deflection of rosette is not analysed. Large numbers of independent measurements of angular displacement were made. Due to the inaccessibility of place where the rosette/strain gauges were placed, results of measurements of angular displacement are not enough precise.
} 
[5] D. Poje: Distribution functions and the estimation of wind power, Croatian meteorological journal, 31, 113, 1996.

[6] T. Burton, D. Sharpe, N. Jenkins, and Ervin Bossanyi: Wind Energy Handbook, John Wiley \& Sons, Ltd, 2001., Chichester.

[7] V. Akhmatov: Analysis of dynamic behaviour of electric power systems with large amount of wind power, $\mathrm{PhD}$ thesis, Electric Power Engineering, Oersted-DTU, Technical University of Denmark, 2003. Available at http://www.studenterpraest.dtu.dk/upload/centre/cet/projekter/05-va-thesis.pdf.

[8] Zhang, J., Yang, S. \& Lin, J.: A nonlinear continuous damage model based on short-crack concept under variable amplitude loading, Fatigue \& Fracture of Engineering Materials \& Structures 39(1), 2016, 7994. DOI: $10.1111 / \mathrm{ffe} .12334$

[9] Lopez-Crespo, P. Mostafavi, M. Steuwer, A. Kelleher, J. F. Buslaps, T.\& Withers, P. J.: Characterisation of overloads in fatigue by 2D strain mapping at the surface and in the bulk, Fatigue \& Fracture of Engineering Materials \& Structures 39(8), 2016, 1040-1048. DOI: 10.1111/ffe.12463

[10] Iacoviello F., Cocco V., D. \& Cavallini M.: Fatigue crack propagation and overload damaging micromechanisms in a ferritic-pearlitic ductile cast iron, Fatigue \& Fracture of Engineering Materials \& Structures 39(8), 2016, 999-1011. DOI: 10.1111/ffe.12443

[11] IEC 61400-12-1:2005-12, INTERNATIONAL STANDARD: Wind turbines, Part 12-1: Power performance measurements of electricity producing wind turbines, First Edition 2005-12

[12] ESDU 74031, INTERNATIONAL STANDARD: Characteristics of atmospheric turbulence near the ground, Part II: Single point data for strong winds, 1974.

[13] ESDU 85020, INTERNATIONAL STANDARD: Characteristics of atmospheric turbulence near the ground, Part II: Single point data for strong winds (neutral atmosphere), (Amended 1993), 1985.

[14] ESDU 86010, INTERNATIONAL STANDARD: Characteristics of atmospheric turbulence near the ground, Part III: Variations in space and time for strong winds (neutral atmosphere), (Amended 1991), 1986.

[15] Petra Lepri, Hrvoje Kozmar, Željko Večenaj and Branko Grisogono: A summertime near-ground velocity profile of the Bora wind, Wind and Structures, Vol. 19, No. 5 (2014) 505-522.

DOI: 10.12989/was.2014.19.5.505

[16] IEC 61400-1:1998, INTERNATIONAL STANDARD: Wind turbines, Part 1: Design requirements, Third Edition, Geneva 1998.

[17] Sten Tronaes Frandsen: Turbulence and turbulence-generated structural loading in wind turbine clusters, $\mathrm{PhD}$ thesis, Technical University of Denmark, Roskilde, January 2007.

[18] P. S. Veers: Three dimensional wind simulations, Technical Report SAND88 - 0512, Sandia National Laboratories, Albuquerque, New Mexico 1988.

[19] IEC/TS 61400-13-1, INTERNATIONAL STANDARD: Wind turbines, Part13-1: Measurement of mechanical loads, Geneva, First Edition 2001-06.

[20] Keil St.: Stress calculation from measured strains in the elastic deformation Range, Hottinger Baldwin Messtechnik GmbH, Darmstadt, Reports in Applied Measurement, Vo1.3 (1987), No.2, pp 56-62.

[21] Keil St.: Zur Eigenspannungsermittlung mit DMS-Bohrlochrosetten, Hottinger Baldwin Messtechnik GmbH, Darmstadt, Messtechnische Briefe 11 (1975) No. 3, pp 53-58.

[22] Müller R.K.: Modellstatische Untersuchungen von Schalentragwerken, Report from Institut für Modellstatik at University of Stuttgart, No. 2, 1973.

[23] Garrad Hassan\&Partners Ltd: Bladed Theory Manual Version 4.2, Bristol 2014.

[24] T. Burton, D. Sharpe, N. Jenkins, E. Bossanyi: Wind energy handbook, John Wiley \& Sons, 2001, Chichester. DOI: 10.1002/0470846062

[25] J.F. Manwell, J.G. McGowan, A.L. Rogers: Wind energy explained, Theory, Design and application, John Wiley \& sons, September 2002.

[26] Alfirević Ivo: Linear structural analysis, Protei, Zagreb 2005

[27] Dassault Systèmes SolidWorks Corporation: Engineering Design and Technology Series Applications with SolidWorks Simulation Instructor Guide, Massachusetts 2010

[28] Hibbeler, R.C.: Structural Analysis (8th ed.), Prentice Hall, Pearson Education, Inc. Upper Saddle River, New Jersey 2012 
[29] Detiček E. Kastrevc M.: Design of Lyapunov based nonlinear position control of electrohydraulc servo systems: Strojniški vestnik ISSN 0039-2480, Mar. 2016, vol. 62 Nr.3 str. 163-170.

DOI: $10.5545 / \mathrm{sv}$-jme.2015.2921

[30] Tadic B., Todorovic P., Novkinic B., Buchmeister B., Radenkovic M., Budak I., Vukelic D. (2015). Fixture Layout Design Based on a Single-Surface Clamping with Local Deformation. Int. Journal of Simulation Modelling, Vol. 14, No. 3, p. 379-391, DOI: 10.2507/IJSIMM14(3)1.280

[31] Zuperl U., Cus F. (2015). Simulation and Visual Control of Chip Size for Constant Surface Roughness. Int. Journal of Simulation Modelling, Vol. 14, No. 3, p. 392-403; DOI: 10.2507/IJSIMM14(3)2.282

[32] Slavković R., Veg A., Dučić N., Slavković N., Baralić J., Miličevič I.: Rigid body dynamics in optimization of the machine tool vibroisolation, Technical gazette, Vol. 22, No. 1, 2015. DOI: $10.17559 / \mathrm{TV}-20130918225023$

Submitted: $\quad 11.8 .2016$

Accepted: $\quad 19.01 .2017$
Miljenko Cvetić

Končar GIM, Fallerovo šetalište 22, 10000 Zagreb. Croatia

Nenad Gubeljak University of Maribor, Faculty of Mechanical Engineering, Smetanova 17, SI-2000 Maribor, Slovenia 